1 A shortcut in forward genetics: concurrent discovery of mutant phenotype and causal mutation 2 in Arabidopsis M2 families via MAD-mapping

3 Danalyn R. Holmes ${ }^{1 \dagger}$, Robert Mobitzer ${ }^{1 \dagger}$, Markus Wunderlich ${ }^{1}$, Hequan Sun ${ }^{2}$, Farid El Kasmi ${ }^{3}$, Korbinian 4 Schneeberger ${ }^{2,4^{*}}$, Thomas Lahaye $^{1^{*}}$

51 ZMBP, General Genetics, University of Tübingen, Auf der Morgenstelle 32, 72076, Tübingen, 6 Germany

72 Max Planck Institute for Plant Breeding Research, Department of Chromosome Biology Carl-von8 Linné-Weg 10, 50829, Cologne, Germany

$9{ }^{3}$ ZMBP, Plant Physiology, University of Tübingen, Auf der Morgenstelle 32, 72076, Tübingen, Germany

$10{ }^{4}$ Faculty of Biology, LMU Munich, Grosshaderner Str. 2, 82152, Planegg-Martinsried, Germany

$11+$ indicates equal contribution (shared first-authors)

$12{ }^{*}$ Corresponding Authors:

13 thomas.lahaye@zmbp.uni-tuebingen.de

14 k.schneeberger@biologie.uni-muenchen.de

ORCID IDs:

16 Danalyn R. Holmes: 0000-0001-6799-8280

17 Robert Morbitzer: 0000-0002-0532-7163

18 Farid El Kasmi: 0000-0002-4634-7689

19 Hequan Sun: 0000-0003-2046-2109

20 Korbinian Schneeberger: 0000-0002-5512-0443

21 Thomas Lahaye: 0000-0001-5257-336X

\title{
22 CLASSIFICATION
}

23 BIOLOGICAL SCIENCES (major) / Plant, Soil, and Microbial Sciences (minor)

\section{KEYWORDS}

EXORIBONUCLEASE 4 (XRN4) / ETHYLENE INSENSITIVE 5 (EIN5), DECAPPING 1 (DCP1), diplontic selection, Transcription activator-like effector (TALE) 


\section{ABSTRACT}

Forward genetics is a powerful tool to establish phenotype-genotype correlations in virtually all areas of plant biology and has been particularly successful in the model plant Arabidopsis. This approach typically starts with a phenotype in an M2 mutant, followed by identifying a causal DNA change in F2 populations resulting from a cross between the mutant and a wildtype individual. Ultimately, two additional generations are needed to pinpoint causal DNA changes upon mutant identification. We postulated that genome-wide allele frequency distributions within the mutants of M2 families facilitate discrimination of causal versus non-causal mutations, essentially eliminating the need for F2 populations. In a proof-of-principle experiment, we aimed to identify signalling components employed by the executor-type resistance $(R)$ protein, Bs4C, from pepper (Capsicum pubescens). In a native setting, $B s 4 C$ is transcriptionally activated by and mediates recognition of the transcription activatorlike effector AvrBs4 from the bacterial pathogen Xanthomonas. Arabidopsis containing an estradiolinducible Bs $4 C$ transgene was used in a conditionally lethal screen to identify second-site suppressor mutations. Whole genome sequencing was used for $\underline{M} 2$ mutant allele-frequency distribution (MAD) mapping in three independent M2 families. MAD-mapping uncovered that all three families harboured mutations in $X R N 4$, a novel component of executor $\mathrm{R}$ protein pathways. Our work demonstrates that causal mutations observed in forward genetic screens can be identified immediately in M2 families instead of derived F2 families. Notably, the timesaving concept of MAD mapping should be applicable to most crop species and will advance the appeal of forward genetics beyond applications in fundamental research.

\section{SIGNIFICANCE}

Forward genetics has uncovered numerous genes that govern plant immune reactions. This procedure relies on mutant plants with modified immune reactions followed by identification of causal DNA changes in derived F2 progeny. We developed a novel forward genetics concept where causal DNA changes are identified in the initial M2 mutants, making time consuming establishment of $F 2$ populations obsolete. To confirm the feasibility of the concept, we mutagenized transgenic Arabidopsis seeds containing the cell death executing resistance gene Bs $4 \mathrm{C}$ from pepper. Whole-genome sequencing of identified mutant families that lack a Bs4C-dependent cell death revealed the XRN4 gene as a novel component of $B s 4 C$-dependent cell death. This confirms our hypothesis that causal mutations can be identified directly within phenotypically selected mutant families. 


\section{INTRODUCTION}

To elucidate the molecular basis of biological phenomena, typically the function or activity of key proteins are studied with the intent of uncovering physical or functional connections with other components. Discovery and validation of the components that are involved in a biological process typically involves a synergistic combination of genetic and biochemical approaches. Speed and analytical power are the major parameters when selecting suitable experimental approaches to identify novel elements of a biological process. Forward genetics has been a key discovery tool for biological processes in Arabidopsis thaliana (Arabidopsis hereafter) and other plant species, since it requires no prior knowledge of the molecular components that are involved in the process of interest, as it solely relies on differential phenotypes (1). In forward genetics, mutagenesis is often used to induce loss-offunction alleles that typically translate into a phenotypic change in M2 individuals that contain the mutation in a homozygous configuration. Traditionally, causal mutations are located by linkage mapping, usually carried out in F2 populations. Such F2 populations are established by the crossing of $M 2$ individuals to wildtype lines, followed by selfing of the F1. The advent of next generation sequencing (NGS) technologies has drastically simplified this process. Using whole-genome sequencing of bulked DNA of mutant recombinants enabled simultaneous mapping and identification of causal mutations in segregating populations using a single sequencing experiment (2). The base pair resolution of wholegenome sequencing technologies also allowed the use of isogenic crosses (i.e. crosses between the mutant and non-mutagenized individual of the same strain) where random background mutations are used as genetic markers instead of natural DNA polymorphisms between plant genotypes $(3,4)$. This had the immediate advantage of bypassing practical challenges caused by phenotypic variation between the parental lines of a regular cross that often complicate visual scoring of a specific mutant phenotype in derived segregating populations.

Utilization of isogenic mapping populations also made way for the elimination of two additional generations after the identification of the M2 mutant phenotypes to generate a mapping population. Instead, selfing of heterozygous M2 mutants generates isogenic M3 mapping populations, thereby minimizing the number of generations needed (5). The disadvantage of this method is that it requires the generation of multiple offspring populations since the heterozygous M2 mutants that are needed to establish M3 mapping populations cannot be phenotypically distinguished from wildtype individuals in the M2 generation. As an alternative to genetic mapping, whole-genome sequencing of multiple allelic mutants in one gene outlines a powerful way to identify causal genes without generating any segregating populations (6). While two allelic mutants can already be sufficient for the identification of a candidate gene, this approach is not free from crossing, as the allelism tests relies on pair-wise intermutant crosses. Consequently, unless allelic mutants of one gene are known and available, identification of causal DNA changes relies on segregating populations that need to be generated after the identification of the mutant phenotype. This time-consuming and tedious task substantially reduces the appeal of forward genetics. Due to this, only a small fraction of available M2 mutants are usually used for follow up analysis. Therefore, a procedure that does not depend on laborious and timeconsuming crosses would enhance the attractiveness of forward genetics.

Plants have two interconnected layers of immunity that collectively provide protection against parasites. Cell surface-localized pattern recognition receptors (PRRs) mediate recognition of conserved pathogen-associated molecular patterns (PAMPs) such as bacterial flagellin (7). To overcome PAMPtriggered immunity (PTI), pathogens have evolved virulence factors known as effectors that are typically translocated into host cells to interfere with PTI and promote disease (8). In response, plants have evolved resistance $(R)$ genes that mediate recognition of microbial effectors. Typically, this effectortriggered immunity (ETI) coincides with a plant cell death reaction (hypersensitive response). In most cases, ETI is mediated by intracellular nucleotide-binding/leucine-rich-repeat proteins (NLRs), where they sense activity and/or structural components of microbial effectors and in turn execute a defence reaction (9-11).

Analysis of plant immune reactions triggered by transcription-activator-like effectors (TALEs) from Xanthomonas uncovered a mechanistically novel plant $R$ gene class where TALEs bind to corresponding effector binding elements within $R$ gene promoters and activate transcription of the downstream encoded $R$ protein $(12,13)$. In such TALE-activated $R$ genes, the encoded $R$ protein is not involved in effector recognition, but only in the execution of the plant immune reaction. Accordingly, these $R$ proteins have been designated executors $(13,14)$. 
bioRxiv preprint doi: https://doi.org/10.1101/2020.06.29.177808; this version posted June 29, 2020. The copyright holder for this preprint (which was not certified by peer review) is the author/funder, who has granted bioRxiv a license to display the preprint in perpetuity. It is made available under aCC-BY-NC-ND 4.0 International license.

\section{RESULTS}

\section{The pepper executor $\mathrm{R}$ protein Bs4C induces plant growth arrest in Arabidopsis}

To identify genes that the pepper executor $\mathrm{R}$ protein Bs4C requires to trigger plant cell death, we initiated a forward genetic screen in the model system Arabidopsis. To do so, we generated a T-DNA encoding an epitope-tagged Bs4C derivative (Bs4C-FLAG-GFP) under the transcriptional control of an estradiol-inducible promoter (Fig. 1A) (17). Agrobacterium tumefaciens mediated transient transformation of Nicotiana benthamiana leaves (agroinfiltration) confirmed that the T-DNA construct mediates cell death in the presence, but not in the absence, of the chemical inducer estradiol, suggesting that the T-DNA construct would confer estradiol dependent Bs $4 C$ expression in transgenic Arabidopsis plants (Fig. 1B). We then transformed the estradiol-inducible Bs4C-FLAG-GFP T-DNA (Estr:Bs4C-FLAG-GFP hereafter) into the Arabidopsis ecotype Columbia (Col-0 hereafter). We inspected seeds of numerous T2 lines to identify ones that showed a strong, estradiol dependent growth inhibition phenotype. Segregation analysis of T2 seeds on kanamycin containing media identified lines that presumably contain a single-copy transgene insertion. T2 lines with a single-copy transgene and strong seedling growth inhibition phenotype were chosen to produce large quantities of T3 seeds for ethyl methanesulfonate (EMS) mutagenesis. Before carrying out EMS mutagenesis, we confirmed functionality of seedling growth inhibition in T3 seeds. To do so, we placed four-day old seedlings into liquid media containing or lacking estradiol, and analysed seedling growth. We found that in the presence, but not in absence of estradiol, the Estr:Bs4C-FLAG-GFP seedlings were severely stunted in their growth (Fig. 1C). By contrast, a transgenic line containing a GFP-GUS reporter gene under expressional control of the estradiol-inducible promoter (Estr:GFP-GUS hereafter) showed no signs of estradiol-dependent growth inhibition. Hence, growth inhibition depends on presence of both the Bs $4 C$ transgene and estradiol. Immunoblot analysis also showed that the Estr:Bs4C-FLAG-GFP transgenic line contained an estradiol-dependent signal matching to the expected $50.6 \mathrm{kDa}$ Bs4C-FLAG-GFP fusion protein (Fig. 1D). Taken together, our data illustrate that the pepper executor R protein Bs4C induces cell death when being expressed in the model plant Arabidopsis. Moreover, the established transgenic Arabidopsis lines containing the Bs4C gene under control of an estradiol-inducible promoter provide the basis for genetic dissection of Bs4C-dependent cell death in Arabidopsis.

\section{A conditionally lethal screen identifies Arabidopsis mutants that do not execute a Bs4C dependent cell death}

To induce randomly distributed mutations across the Arabidopsis genome, approximately 10,000 Estr:Bs4C-FLAG-GFP T3 (M0) seeds were treated with EMS and planted into soil. Corresponding M1 plants were individually bagged, and derived M2 seeds were harvested, creating 4,000 M2 families. About 100 seeds of each M2 family, equating to approximately 400,000 M2 seeds in total, were studied as representatives for the entire M2 families. Seeds were allowed to grow on agar plates containing estradiol in an effort to identify second-site suppressor mutants that inhibit Bs4C-dependent cell death. After 14 days, most seedlings had stopped growing and neglected cotyledon emergence (Fig. $2 A$ ). M2 families containing putative suppressor mutations were easily detectable, as they were large in size and developed roots and true leaves with a green colour similar to Estr:GFP-GUS (Fig. 2B). A total of 
bioRxiv preprint doi: https://doi.org/10.1101/2020.06.29.177808; this version posted June 29, 2020. The copyright holder for this preprint (which was not certified by peer review) is the author/funder, who has granted bioRxiv a license to display the preprint in perpetuity. It is made available under aCC-BY-NC-ND 4.0 International license.

$46 \mathrm{M} 2$ families contained individual plants that grew like Estr:GFP-GUS plants on estradiol-containing agar plates. A low percentage of survivors within most M2 families suggests recessive inheritance of suppressor alleles. Survivors from each M2 family were transplanted from estradiol plates to soil for further investigation. Here, we present the analysis of three representative ace mutant families.

\section{ace mutants show no systemic cell death despite having a functional Bs $4 C$ gene}

Two classes of mutations were expected to be identified from our forward genetic screen: those that are within putative signalling and/or regulatory components that Bs $4 \mathrm{C}$ requires to induce plant cell death, and those that are within the transgene and affect expression and/or functionality of Bs4C. To exclude plants that did not accumulate similar levels of Bs4C protein to that of the parental line, we analysed Bs4C protein expression in ace 1, ace2, and ace 3 mutants by immunoblot analysis. In all three ace mutants, immunoblot analysis highlighted signals matching to the expected $50.6 \mathrm{kDa}$ Bs4C-FLAGGFP fusion protein (Fig. 2D, Fig. S1). Moreover, we PCR-amplified and sequenced the Bs $4 C$ coding sequence (CDS) in all three ace mutants' families and found that they all contained the wildtype Bs4C CDS.

\section{Segregation in ace M2 seeds does not fit to the expected 1:7 ratio}

Arabidopsis M1 seeds contain two diploid cells that give rise to generative organs (inflorescence) of M1 plants that can be phenotypically studied in the M2 generation $(1,18)$. If EMS mutagenesis induces a mutation in one of the two diploid M1 precursor cells, this translates into a 1:7 phenotypical segregation of bulked M2 family seeds, assuming recessive inheritance. Thus $12.5 \%$ of the seeds of each ace M2 family are expected to survive on agar plates containing estradiol. We plated several hundred M2 seeds for each of the three ace families on agar plates containing estradiol and observed survival rates of $6.1 \%(45 / 734), 2.0 \%(17 / 833)$, and $5.1 \%(57 / 1114)$ for ace 1 , ace2, and ace3 mutant families, respectively. Given the clear phenotype in all three ace mutant families and the large number of studied M2 seeds, it seems unlikely that deviations of observed versus expected segregation ratios are due to errors in phenotypical scoring. Thus, the observed distorted segregation is possibly the consequence of diplontic selection, a process of competition between cells within a meristem that can result in reduced proliferation of mutated cells (19).

\section{Segregation of EMS mutations in ace M2 families provides a basis to identify causal mutations}

Irrespective of the observed segregation data, such M2 plants that grow in the presence of estradiol (survivors) should have the causal mutation exclusively in the homozygous configuration, assuming recessive inheritance. By contrast, non-causal mutations are expected to segregate randomly in M2 survivors with exception of those that are linked to the causal mutations. NGS-mediated analysis of the allele frequency for each EMS mutation within a pool of survivors from one M2 family can therefore reveal mutations that are homozygous across all M2 survivors in one family and that are potentially causal for the observed cell death suppression phenotype (Fig. 3). We termed this concept as $\underline{M} 2$ mutant allele-frequency distribution (MAD) mapping and studied the feasibility of MAD-mapping in three representative ace mutant families.

\section{Three ace families have distinct mutations in the Arabidopsis XRN4IEIN5 gene}

Whole-genome sequencing was performed on the parental line that was originally used for EMS mutagenesis (Estr:Bs4C-FLAG-GFP) and three distinct DNA pools composed of survivors from ace1, ace2, and ace 3 families, respectively. The DNA pools of ace1, ace2, and ace3, contained 38, 18, and 25 M2 survivors, respectively. Paired end sequencing was used with a minimum depth of $150 \mathrm{X}$ coverage to determine EMS mutations and their allele frequencies in ace1, ace2, and ace 3 M2 families (Fig. 4, Fig. S2-S4, Table S1). We detected 60, 150, and 487 EMS mutations specific for the ace1, ace2, and ace $3 \mathrm{M} 2$ families, respectively. Scanning the pooled genomes of M2 survivors for a selectioninduced increase in the frequency of mutant alleles, we identified genomic regions with increased (and locally fixed) mutant allele frequencies on chromosome 1 for all three ace mutants (Fig 4). In order to select candidate mutations in these genomic regions that possibly cause the observed cell death suppression phenotype, we limited our search for causal mutations by considering only EMS mutations with an allele frequency of 0.95 or higher. Moreover, our search was restricted to base pair changes that are characteristic to EMS-induced mutations (C to $T$ or $G$ to $A$ ). We disregarded mutations that occurred in either the non-coding regions (intronic or untranslated regions) or caused synonymous mutations in the coding regions, thereby focusing on missense and nonsense mutations in coding regions. This narrowed our search down to one candidate gene in ace 1 and ace2 pools (AT1G54490.1), 
and to three candidate genes in the ace3 pool (AT1G54490.1, AT1G52940.1, and AT1G55110.1). AT1G54490.1, which encodes the EXORIBONUCLEASE 4 (XRN4) / ETHYLENE INSENSITIVE 5 (EIN5) protein (Fig. 4) (20-22), was found to be mutated across all three ace families, indicating the functional impact of mutations in this specific CDS on the common phenotype. As one would expect, each M2 family had distinct mutations in the coding region of AT1G54490.1 (Fig. 5, Fig. S5). The ace1 mutation lies within the sixth exon, and changes the wildtype aspartate to an asparagine (D to N). The ace 2 mutation is in the eighth exon, and changes the wildtype tryptophan to a premature stop codon (W to *). The ace3 mutation is found in the third exon of AT1G54490.1, and alters the parental or wildtype amino acid of an alanine to a valine (A to V) (Fig. 5).

Altogether, our data suggests that the identified XRN4/EIN5 mutant alleles abolish Bs4C dependent cell death in Arabidopsis. Moreover, our data demonstrates that MAD-mapping is a highlyefficient approach for identification of causal mutations in M2 mutant families.

\section{DISCUSSION}

We demonstrated that the estradiol-inducible expression of the pepper executor-type R protein Bs4C triggers systemic cell death in transgenic Arabidopsis plants. This conditionally lethal phenotype was used in a forward genetic screen to identify three distinct Arabidopsis ace mutants that do not execute Bs4C-dependent plant cell death. We determined the frequency of EMS-mutations in three distinct ace M2 families, a process that we designated as MAD-mapping. This identified mutations for all three M2 families within AT1G54490.1, which encodes the exoribonuclease XRN4 (22).

As of yet, XRN4 is the first known genetic component required for cell death triggered by executor-type R proteins. XRN4 is the plant cytoplasmic homolog of yeast and metazoan XRN1, and catalyses degradation of uncapped mRNAs from the $5^{\prime}$ end $(23,24)$. In a simplistic model, XRN4 could degrade a transcript encoding a negative regulator of the Bs4C-dependent cell death. Absence of functional XRN4 in ace mutant plants would presumably cause increased expression of the putative negative regulator and inhibit Bs4C-triggered cell death, being consistent with the observed mutant phenotype.

Recent studies uncovered that PAMP-induced activation of PRRs results in phosphorylation of the DECAPPING 1 (DCP1) protein that in turn, interacts with and activates XRN4 (25). It is assumed that activated XRN4 degrades transcripts encoding positive and negative regulators of PRR-triggered immune reactions. It is therefore conceivable that XRN4 could be a shared regulator of PRR- and executor R protein-triggered immune pathways. Future studies will have to clarify the exact role of XRN4 in Bs4C-dependent cell death reactions, and whether or not XRN4 is also involved in other plant defence pathways.

Forward genetic screens and subsequent isolation of causative mutations by positional cloning is an essential gene discovery tool for elucidation of any kind of biological process in plants (26). The advent of next-generation sequencing technology introduced several innovations into the process of mutation identification, including simultaneous mapping and identification of causal mutations as well as the utilization of isogenic mapping populations $(3,4)$. Unless allelic groups are available, mutation identification still relies on the time-consuming process of generating numerous segregating populations. Therefore, the workload and time that is needed to establish segregating populations remains a major limitation in forward genetics. We postulated and experimentally validated that the segregation of causal mutations in M2 families, which is regularly used for the initial identification of mutant phenotypes, can already be used to identify causal mutations, ultimately removing the need for tedious generation of segregating populations. Therefore, upon mutagenesis of seeds, only two generations are needed to identify causal mutations. Given the generation time of approximately 8 weeks in Arabidopsis, it essentially takes less than one year to identify causal mutations via MADmapping. While we demonstrated the feasibility of MAD-mapping in the model plant Arabidopsis, the concept could be applicable to any plant and even non-plant species.

We combined MAD-mapping with a conditionally lethal screen (Fig. 3); and a benefit of this combination is that it can be carried out at the seedling stage. Accordingly, large numbers of mutants can be studied in a short time and the need for space remains quite limited. Plant defence reactions typically rely on the execution of cell death reactions, and as a result, several conditionally lethal screens have been conducted in the past to study plant $R$ proteins and to identify signalling components of $R$ pathways (27-29). These screens depend on inducible promoters that typically contain constitutively expressed elements. For example, the estradiol-inducible system that we used contains the 
bioRxiv preprint doi: https://doi.org/10.1101/2020.06.29.177808; this version posted June 29, 2020. The copyright holder for this preprint (which was not certified by peer review) is the author/funder, who has granted bioRxiv a license to display the preprint in perpetuity. It is made available under aCC-BY-NC-ND 4.0 International license.

constitutively expressed synthetic transcription factor XVE that is activated by estradiol (Fig. 1). It has been noted in the past, that estradiol-inducible transgenes lose inducibility throughout generations (30). This phenomenon typically starts in the T4 and T5 generations and is likely the consequence of transgene silencing. We identified causal mutations in the M2 generation, which corresponds to the T5 generation (Fig. 3). In previous studies, we used the estradiol-inducible system in a conventional forward genetic screen and established conventional F2 mapping populations, which corresponds to the T7 generation, to identify causal mutations for given M2 survivors. However, we did not observe the expected segregation of cell death in F2 individuals and ultimately could not identify causal mutations by this approach, possibly caused by transgene silencing in the F2/T7 mapping generation. In MADmapping, phenotypic identification and isolation are both carried out in the M2 generation, essentially overcoming the problem of gene silencing that possibly occurs in mapping populations derived from a single transgenic M2 plant.

While the principle of MAD-mapping is broadly applicable, it cannot be carried out on bulked M2 populations since it is based on the analysis of individual M2 families. Accordingly, after EMS mutagenesis, each M1 plant must be harvested individually to generate a collection of M2 families. Similarly, each M2 family must be studied individually for phenotypic changes. Although MAD-mapping is generally time-saving, it is more laborious in the harvesting and screening phase than conventional screens that are typically based on bulked M2 seeds. On the upside, however, screening of separate M2 families offers the possibility for recovering mutations that are infertile when homozygous via the heterozygous siblings of the mutant plants. Moreover, this strategy guarantees the independence of mutants isolated from distinct M2 families. In the long run, while the analysis of M2 families is more laborious than analysis of bulked M2 seeds, the benefits of MAD mapping vastly overcome the shortterm extra work that is required.

Overall, we envision that the ease and speed of MAD-mapping will substantially increase the attraction of forward genetic approaches and it stands to reason that MAD-mapping will make a major contribution towards the elucidation of biological pathways in the near future.

\section{MATERIALS AND METHODS}

\section{Plant material and growth conditions}

Arabidopsis thaliana plant material used in this study: Col-0, Estr:Bs4C-FLAG-GFP, Estr:GFP-GUS, ace 1 family, ace 2 family, ace 3 family. For the seedling growth assay, seeds were sterilized using $80 \%$ ethanol and $0.05 \%$ Triton X-100 solution, and left to stratify in the darkness at $4 \mathrm{C}$ for two days on $1 / 2$ MS plates $(0.43 \%$ (w/v) MS Salts (Gibco), $1 \%$ (w/v) Sucrose, $0.05 \%$ MES, pH 5.8) containing $200 \mu \mathrm{g} / \mathrm{mL}$ Cefotaxim. Seeds were put to long day (16hr light/8hr dark) at $20^{\circ} \mathrm{C}$ in light and $18{ }^{\circ} \mathrm{C}$ in dark for four days. On the fourth day, seedlings were transplanted to 48-well plate, each well containing either 20 $\mu \mathrm{M}$ estradiol, or mock treatment $(1 \%(\mathrm{v} / \mathrm{v}) \mathrm{DMSO})$, and left for 10 more days. On the $14^{\text {th }}$ day, seedling growth was analysed. For seedling immunoblot detection, four 14 day old seedlings of each genotype were placed in either $20 \mu \mathrm{M}$ estradiol or $1 \%$ DMSO, vacuum infiltrated, and left at room temperature for 24 hours. Samples were then flash frozen and used for immunodetection, as described below. For EMS mutagenesis, approximately $200 \mathrm{mg}$ of Estr:Bs4C-FLAG-GFP Arabidopsis seeds were allowed to swell in water for 3 days. Afterwards, these seeds were incubated in $50 \mathrm{~mL}$ of $0.3 \%$ EMS solution for 6 hours, shaking. The seeds were then transferred to a Nalgene Filter Unit and washed six times with water. The seeds were then resuspended in $0.1 \%$ phytoagar and sowed on soil. After 10 days, the seedlings were transplanted into individual pots in an outdoor greenhouse $(16 \mathrm{hr}$ light/8hr dark, temperature minimum $18^{\circ} \mathrm{C}$, no humidity control). These individual plants now generated the M1 population. After 6 weeks, seeds from each individual M1 plant were harvested, creating 4000 individual M2 families. For the screening of ace families, 100 seeds of each of the $4000 \mathrm{M} 2$ families were placed in a 96 well plate, and were gas sterilized ( $80 \mathrm{~mL} \mathrm{NaClO}$ and $3 \mathrm{~mL} 32 \% \mathrm{HCl}$ solution) overnight. The following day, $200 \mu \mathrm{L}$ of $1 \%$ phytoagar was placed in each well, sealed, and left to stratify at $4{ }^{\circ} \mathrm{C}$ in the dark for 2 days. The seeds were then plated on $1 / 2$ MS plates (described previously) containing $20 \mu \mathrm{M}$ estradiol, and put to long day. Plates were left for 14 days, suppressing families were selected, and survivors were transplanted to soil. Five week old plants were used for immunodetection by taking three $4 \mathrm{~mm}$ punches and vacuum infiltrating them with $20 \mu \mathrm{M}$ estradiol, and letting them sit for 24 hours before flash freezing and going forward with immunodetection (as described below). To sequence the transgene, gDNA was collected from leaf tissue, PCR amplified, and sent for Sanger sequencing. 
For Estr:Bs4C-FLAG-GFP and Estr:GFP-GUS T-DNA constructs coding sequences of Bs4C, 3xFlag, GFP and uidA were PCR amplified and cloned via GoldenGate cloning into pENTR CACC-AAGG. Resulting pENTR-Bs4C-FLAG-GFP and pENTR-GFP-GUS were used in LR reaction together with pER10-GW generating pER10-Bs4C-FLAG-GFP and pER10-GFP-GUS.

\section{Transgenic lines}

Estr:Bs4C-FLAG-GFP and Estr:GFP-GUS were generated using Agrobacterium GV3101 containing pER10-Bs4C-FLAG-GFP or pER10-GFP-GUS in a floral dip method. Transgenic $A$. thaliana were selected with Kanamycin on $1 / 2$ MS plates.

\section{Genomic DNA extraction}

Approximately $100-150 \mathrm{mg}$ of leaf material was collected. $600 \mu \mathrm{L}$ of CTAB buffer (100 mM Tris- $\mathrm{HCl} \mathrm{pH}$ 8.0, $20 \mathrm{mM}$ EDTA, $1.4 \mathrm{M} \mathrm{NaCl}, 2 \%(\mathrm{w} / \mathrm{v})$ cetyltrimethyl ammonium bromide) was added, and homogenized using a vortex. Samples were incubated at $65^{\circ} \mathrm{C}$ for 30 minutes. Heated samples were spun down at room temperature. $500 \mu \mathrm{L}$ of the supernatant was transferred to a new tube. $2.5 \mu \mathrm{L}$ of RNAse A (10 mg/mL, ThermoFisher) was added, and gently vortexed, and incubated at $37{ }^{\circ} \mathrm{C}$ for 30 min. $500 \mu \mathrm{L}$ of chloroform was added, and mixed. Samples were spun down at room temperature, and $450 \mu \mathrm{L}$ of the aqueous phase was added to a new tube. $450 \mu \mathrm{L}$ of $100 \%$ isopropanol was added, and gently mixed. The tubes were then spun down until a pellet formed, and the supernatant was discarded. $500 \mu \mathrm{L}$ of $70 \%$ ethanol was added, mixed, spun down at room temperature, and then the supernatant was discarded. This was repeated twice. The pellet was then dried at $35^{\circ} \mathrm{C}$. The dried pellet was

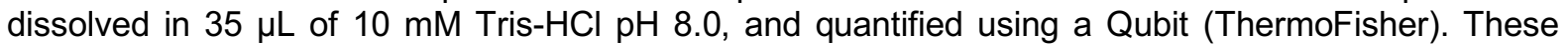
samples were then sent for NGS.

\section{Next generation sequencing and mapping populations}

Raw reads of each sample were aligned to Col-0 reference genome (The Arabidopsis Genome Initiative 2000; www.arabidopsis.org) using GenomeMapper (31), after which short-read alignments were corrected for read-pair information and consensus bases were called with shore (31). After removing common SNPs between each mutant and the parental line, the causal mutation of each mutant was predicted by analysing allele frequencies with SHOREmap v3.0 $(2,32)$.

\section{Immunoblotting}

Samples were flash frozen and then ground to a fine powder. $50 \mu \mathrm{L}$ of SDS loading buffer ( $50 \mathrm{mM}$ TrisHCL pH 6.8, $100 \mathrm{mM}$ DTT, $2 \%$ SDS, $0.1 \%$ bromophenol blue, $10 \%$ glycerol) was added, and boiled at $95 \mathrm{C}$ for $10 \mathrm{~min}$. Samples were loaded onto a SDS-polyacrylamide gel (4\% stacking, $10 \%$ resolving), and then transferred to a PVDF-membrane (BioRad). Samples were blocked in $5 \%$ milk/1X TBST (50 $\mathrm{mM}$ Tris- $\mathrm{HCl}, 150 \mathrm{mM} \mathrm{NaCl}, 0.05 \%$ Tween-20), and anti-bodies were then applied. Anti-FLAG primary antibody (F1804, Sigma-Aldrich) raised in mouse, at 1:5000 dilution, was used, shaking overnight. The next day, membranes were washed with 1X TBST ( $50 \mathrm{mM}$ Tris base, $150 \mathrm{mM} \mathrm{NaCl}, 0.05 \%$ (v/v) Tween20), and the anti-mouse-HRP secondary antibody (A9044, Sigma-Aldrich) was used at a 1:2500 dilution, and incubated for 2 hours. Anti-GFP-HRP conjugated primary antibody (SC-9996, SantaCruz) at 1:2500 dilution was used, and incubated for 2 hours. The blot was washed 3 times with 1X TBST, and once with 1X TBS (1X TBST, but no Tween-20 added). The Clarity ECL Substrate (BioRad) and the Amersham ${ }^{\mathrm{TM}}$ Imager 600 (GE Life Sciences) machine were used for imaging. All membranes were stained with Ponceau. 


\section{ACKNOWLEDGEMENTS}

The work was supported by the Deutsche Forschungsgemeinschaft (DFG) [SFB 1101 to T. Lahaye (project D08) and F. El Kasmi (project D09) and LA 1338/7-1 to T. Lahaye]. Research by K. Schneeberger was funded by the DFG under Germany's Excellence Strategy - EXC 2048/1 390686111, and the European Research Council (ERC) Grant "INTERACT" (802629). We thank E. S. Ritchie and A. Strauß for helpful comments on this manuscript, and S. Üstün for insightful discussions. We would like to thank A. Dressel, N. Gallas, P. Gouguet, P. Lutz, T. Phan, E. S. Ritchie, K. Schenstnyi, L. Schmaltz, S. Schade, A. Strauß, D. Wu, and Y. You for their help with separating and collecting M1 plants, as well the ZMBP gardeners for taking care of these plants.

385

386

\section{CONFLICTS OF INTEREST}

The authors have no conflicts of interest to report.

\section{FIGURE LEGENDS}

Figure 1. Bs4C induces growth arrest in Arabidopsis.

A | A T-DNA construct for estradiol-inducible expression of the pepper executor protein Bs4C. Driven by the constitutive G10-90 promoter, the XVE gene translates into a chimeric transcriptional activator that contains an estrogen receptor domain. When estrogen $(E)$ is present (here in the form of $\beta$ estradiol), it binds to the XVE protein, mediates XVE homodimerization and enables XVE to bind to the LexA operator (OlexA). This induces transcription of the downstream gene encoding a Bs4C-FLAGGFP protein. The Bs4C fusion protein requires the putative signaling elements $A, B, C$ to trigger plant cell death. Methylation of the G10-90 promoter (M) can cause transcriptional silencing of the G10-90 promoter and results in a non-inducible promoter.

B | A Bs $4 C$ transgene triggers estradiol-dependent cell death in Nicotiana benthamiana leaves. The depicted T-DNA constructs were delivered into $N$. benthamiana leaves via Agrobacterium mediated transient transformation. Leaf areas into which the inducer estradiol was infiltrated are highlighted with a red line.

C | An inducible Bs $4 C$ transgene triggers systemic cell death in Arabidopsis. Four day old seedlings of indicated genotypes were placed in liquid media either containing estradiol or a lacking estradiol (Mock). Ten days later, the seedlings show cell death in presence of estradiol and the $B s 4 C$ transgene.

D | Immunoblot analysis using anti-FLAG antibody of tissue from two week old Arabidopsis seedlings of depicted genotypes (Col-0, Estr:Bs4C-FLAG-GFP, Estr:GFP-GUS). Plants were incubated for 24 hours in liquid media either containing estradiol or lacking estradiol (mock). Ponceau stained membrane serves as a loading control.

Figure 2. ace screen identifies suppressors of Bs4C-dependent cell death in Arabidopsis.

A I Identification of the ace 3 M2 family. Seeds of twelve distinct M2 families are placed in rows on estradiol-containing agar. Boxes framed by dashed lines indicate the region that is covered by seeds of one M2 family. One M2 family (ace3; bottom right) contains individual M2 plants that grow despite the presence of the inducer chemical.

B | Estradiol triggers a Bs4C-dependent cell death reaction. Seeds containing either an estradiolinducible Bs4C (Estr:Bs4C-FLAG-GFP) or a GFP-GUS reporter gene (Estr:GFP-GUS) were placed on an estradiol-containing agar plate.

C | Bs4C protein is expressed in different ace mutants. Immunoblot analysis of five week old Arabidopsis leaves treated with estradiol for 24 hours. Bs $4 C$ was detected using an anti-FLAG antibody. Ponceau stain provides an info on total protein content in the samples. 
Figure 3. MAD-mapping excludes crosses to expedite isolation of causative mutation.

MAD-mapping identifies causal mutations in the M2 generation. The parental transgenic line (P/T3) contains an inducible transgene (not indicated) that triggers systemic cell death (black skull) upon application of estradiol. Seeds of the parental line were mutagenized by EMS treatment (red arrow) producing M1/T4 plants with EMS-induced mutations (ovals). The causal mutation (red oval), that inhibits activity of the inducible transgene is heterozygous in the M1. EMS mutations of a given M1 segregate in M2/T5 descendants. M2 plants that are homozygous for the causal mutation will survive in presence of the inducer chemical. Survivors of a given M2 family are used to generate DNA pools in which the frequency of EMS-induced mutations is determined by next generation sequencing (NGS). The causal mutation will be homozygous in all survivors and thus will be present at a frequency of 1 $(100 \%)$ in the pool DNA.

430 Figure 4. M2 allele frequency-distribution (MAD) mapping identifies mutations in AT1G54490.1 that suppress Bs4C-dependent cell death.

The frequency of EMS-induced mutations (red dots) on chromosome 1 is displayed for ace 1, ace 2 and ace3 DNA pools. Boxes provide information on mutations that occur at frequencies of 0.95 or higher. Italic font indicates the chromosomal location of the mutation with the frequency provided in square brackets. Boldface font provides the gene designation. If the mutation is within a gene, the third row reveals the consequences of this mutation. Underlining indicates that the given mutation has likely functional consequences.

Figure 5. ace families harbor distinct mutations in AT1G54490.1.

A | Location of mutations in ace1, ace2, and ace 3 mutants. Black boxes represent AT1G54490.1 exons. The location of each causal mutations in ace3, ace1, and ace2, is indicated. Black bar indicates length of $500 \mathrm{bp}$.

B | Mutations in ace mutants and its consequences at the protein level. Underlined letters indicate the affected codons with the encoded amino acid shown below. Letters in black bold display the base pair or amino acid found in the parental line. Red bold font indicates EMS-induced mutations with the encoded amino indicated below. Numbers above mutated base pairs indicate positions of the mutations within the transcript sequence. An asterisk $\left(^{*}\right)$ indicates a translational stop codon.

\section{SUPPLEMENTAL FIGURES}

Figure S1. | Transgenic lines containing inducible transgenes express transgene-encoded proteins in an estradiol-dependent fashion. Immunoblot analysis using anti-FLAG and anti-GFP antibody of tissue from two week old Arabidopsis seedlings of depicted genotypes (Col-0, Estr:Bs4CFLAG-GFP, Estr:GFP-GUS). Plants were incubated for 24 hours in liquid media either containing estradiol or lacking estradiol (mock). Ponceau stained membrane serves as a loading control. Molecular mass markers are indicated by triangles.

Figure S2. | M2 allele frequency-distribution in the ace1 mutant family. The frequency and position of EMS-induced mutations (red dots) on chromosome 1-5 are displayed.

Figure S3. | M2 allele frequency-distribution in the ace2 mutant family. The frequency and position of EMS-induced mutations (red dots) on chromosome 1-5 are displayed.

Figure S4. | M2 allele frequency-distribution in the ace3 mutant family. The frequency and position of EMS-induced mutations (red dots) on chromosome 1-5 are displayed.

460 Figure S5. | Mutations in ace families are independent from one another. Underlined letters indicate the 3 letter codon corresponding to the amino acid directly below. Letters in black bold display reference base pair or amino acid found in the parental line, and letters in red bold designate altered 
bioRxiv preprint doi: https://doi.org/10.1101/2020.06.29.177808; this version posted June 29,2020 . The copyright holder for this preprint (which was not certified by peer review) is the author/funder, who has granted bioRxiv a license to display the preprint in perpetuity. It is made available under aCC-BY-NC-ND 4.0 International license.

MAD-mapping : a shortcut in forward genetics $-11-$

SUPPLEMENTAL TABLES

466 Table S1 - EMS-induced mutations with increased allele frequency in Arabidopsis ace mutants.

Table S1. Allele frequencies of EMS-induced SNPs in three ace families.

\begin{tabular}{|c|c|c|c|c|c|c|c|c|c|}
\hline Family & Position & Ref./Alt. & Cover. & $\begin{array}{l}\text { Allele } \\
\text { freq. }\end{array}$ & Gene ID & Feature & $\begin{array}{c}\text { CDS } \\
\text { position }\end{array}$ & Effect & Change \\
\hline \multirow{2}{*}{ ace 1} & $18,641,436$ & $\mathrm{G} / \mathrm{A}$ & 81 & 0.77 & - & intergenic & & & \\
\hline & $20,352,190$ & $\mathrm{G} / \mathrm{A}$ & 98 & 0.97 & AT1G54490.1 & CDS & 706 & Nonsyn & $\mathrm{D} / \mathrm{N}$ \\
\hline \multirow{7}{*}{ ace2 } & $18,117,826$ & $\mathrm{G} / \mathrm{A}$ & 61 & 0.85 & AT1G48970.1 & 5' UTR & & & \\
\hline & $19,031,508$ & G/A & 61 & 0.87 & - & intergenic & & & \\
\hline & $20,105,279$ & $\mathrm{G} / \mathrm{A}$ & 59 & 0.97 & AT1G53850.1 & intronic & & & \\
\hline & $20,105,279$ & $\mathrm{G} / \mathrm{A}$ & 59 & 0.97 & AT1G53850.2 & intronic & & & \\
\hline & $20,352,595$ & $\mathrm{G} / \mathrm{A}$ & 44 & 0.98 & AT1G54490.1 & CDS & 911 & Nonsyn & $\mathrm{W} /{ }^{*}$ \\
\hline & $20,765,374$ & $\mathrm{G} / \mathrm{A}$ & 59 & 1 & AT1G55580.1 & CDS & 1269 & Syn & $\mathrm{Q} / \mathrm{Q}$ \\
\hline & $21,402,987$ & $\mathrm{G} / \mathrm{A}$ & 47 & 0.96 & - & intergenic & & & \\
\hline \multirow{10}{*}{ ace3 } & $18,062,237$ & $\mathrm{C} / \mathrm{T}$ & 101 & 0.9 & AT1G48840.1 & intronic & & & \\
\hline & $19,722,708$ & $\mathrm{C} / \mathrm{T}$ & 129 & 0.98 & AT1G52940.1 & CDS & 478 & Nonsyn & $H / Y$ \\
\hline & $20,351,467$ & $\mathrm{C} / \mathrm{T}$ & 146 & 0.99 & AT1G54490.1 & CDS & 329 & Nonsyn & $\mathrm{A} / \mathrm{V}$ \\
\hline & $20,386,527$ & $\mathrm{C} / \mathrm{T}$ & 102 & 0.99 & - & intergenic & & & \\
\hline & $20,560,738$ & $\mathrm{C} / \mathrm{T}$ & 139 & 0.95 & AT1G55110.1 & CDS & 1036 & Nonsyn & $E / K$ \\
\hline & $20,613,630$ & $\mathrm{C} / \mathrm{T}$ & 98 & 0.88 & - & intergenic & & & \\
\hline & $20,616,883$ & $\mathrm{C} / \mathrm{T}$ & 96 & 0.89 & - & intergenic & & & \\
\hline & $20,830,617$ & $\mathrm{C} / \mathrm{T}$ & 123 & 0.95 & AT1G55720.1 & 5‘ UTR & & & \\
\hline & $21,512,799$ & $\mathrm{C} / \mathrm{T}$ & 130 & 0.93 & AT1G58100.1 & CDS & 1087 & Nonsyn & $\mathrm{G} / \mathrm{S}$ \\
\hline & $21,512,799$ & $\mathrm{C} / \mathrm{T}$ & 130 & 0.93 & AT1G58100.2 & CDS & 1015 & Nonsyn & $\mathrm{G} / \mathrm{S}$ \\
\hline
\end{tabular}

SNPs identified on Arabidopsis chromosome 1 in ace1, ace2 and ace 3 M2 families, stating the position, the reference base (Ref.), identified altered base (Alt.), the coverage (Cover), allele frequency (Allele freq.), the annotated Gene ID, the feature within the gene, the coding sequence position (CDS position), the effect of the mutation, and the resulting amino acid change (Change). SNPs that were below an allele frequency of 0.77 are not listed. Underlined font indicates the gene that was identified in all three ace families. 


\section{REFERENCES}

470

471

472

473

474

475

476

477

478

479

480

481

482

483

484

485

486

487

488

489

490

491

492

493

494

495

496

497

498

499

500

501

502

503

504

505

506

507

508

509

510

511

512

513

514

515

1. D. R. Page, U. Grossniklaus, The art and design of genetic screens: Arabidopsis thaliana. Nat. Rev. Genet. 3, 124-136 (2002).

2. K. Schneeberger et al., SHOREmap: simultaneous mapping and mutation identification by deep sequencing. Nat. Methods 6, 550-511 (2009).

3. A. Abe et al., Genome sequencing reveals agronomically important loci in rice using MutMap. Nat. Biotechnol. 30, 174-178 (2012).

4. B. Hartwig, G. V. James, K. Konrad, K. Schneeberger, F. Turck, Fast isogenic mapping-bysequencing of ethyl methanesulfonate-induced mutant bulks. Plant Physiol. 160, 591-600 (2012).

5. R. Fekih et al., MutMap plus : genetic mapping and mutant identification without crossing in rice. PLoS One 8 (2013).

6. K. J. V. Nordström et al., Mutation identification by direct comparison of whole-genome sequencing data from mutant and wild-type individuals using k-mers. Nat. Biotechnol. 31, 325330 (2013).

7. J. M. Zhou, Y. Zhang, Plant Immunity: danger perception and signaling. Cell 181, 978-989 (2020).

8. J. D. Jones, J. L. Dangl, The plant immune system. Nature 444, 323-329 (2006).

9. S. van Wersch, L. Tian, R. Hoy, X. Li, Plant NLRs: the whistleblowers of plant immunity. Plant Communications 1, 100016 (2020).

10. P. Li, Y. J. Lu, H. Chen, B. Day, The lifecycle of the plant immune system. Crit. Rev. Plant Sci. 39, 72-100 (2020).

11. S. Lolle, D. Stevens, G. Coaker, Plant NLR-triggered immunity: from receptor activation to downstream signaling. Curr. Opin. Immunol. 62, 99-105 (2020).

12. J. Boch, U. Bonas, T. Lahaye, TAL effectors - pathogen strategies and plant resistance engineering. New Phytol. 204, 823-832 (2014).

13. J. Zhang, Z. Yin, F. White, TAL effectors and the executor $R$ genes. Front. Plant Sci. 6, 641 (2015).

14. A. J. Bogdanove, S. Schornack, T. Lahaye, TAL effectors: finding plant genes for disease and defense. Curr. Opin. Plant Biol. 13, 394-401 (2010).

15. C. Krönauer, J. Kilian, T. Strauß, M. Stahl, T. Lahaye, Cell death triggered by the YUCCA-like Bs3 protein coincides with accumulation of salicylic acid and pipecolic acid but not of indole-3acetic acid. Plant Physiol. 180, 1647-1659 (2019).

16. T. Strauß et al., RNA-seq pinpoints a Xanthomonas TAL-effector activated resistance gene in a large crop genome. Proc. Natl. Acad. Sci. USA 109, 19480-19485 (2012).

17. J. Zuo, Q. W. Niu, N. H. Chua, Technical advance: An estrogen receptor-based transactivator XVE mediates highly inducible gene expression in transgenic plants. Plant J. 24, 265-273 (2000).

18. G. Jürgens, U. Mayer, R. A. T. Ruiz, T. Berleth, S. Misera, Genetic-analysis of pattern-formation in the Arabidopsis embryo. Development, 27-38 (1991).

19. G. H. Balkema, Diplontic drift in chimeric plants. Radiat. Bot. 12, 51-55 (1972).

20. T. Potuschak et al., The exoribonuclease XRN4 is a component of the ethylene response pathway in Arabidopsis. Plant Cell 18, 3047-3057 (2006).

21. F. F. Souret, J. P. Kastenmayer, P. J. Green, AtXRN4 degrades mRNA in Arabidopsis and its substrates include selected miRNA targets. Mol. Cell 15, 173-183 (2004).

22. S. Gazzani, T. Lawrenson, C. Woodward, D. Headon, R. Sablowski, A link between rnRNA turnover and RNA interference in Arabidopsis. Science 306, 1046-1048 (2004). 
23. T. Chantarachot, J. Bailey-Serres, Polysomes, stress granules, and processing bodies: a dynamic triumvirate controlling cytoplasmic mRNA fate and function. Plant Physiol. 176, 254269 (2018).

24. R. U. A. Camacho, A. Lokdarshi, A. G. von Arnim, Translational gene regulation in plants: a green new deal. Wires RNA ARTN e1597

25. X. Yu et al., Orchestration of processing body dynamics and mRNA decay in Arabidopsis immunity. Cell Rep. 28, 2194-2205 e2196 (2019).

26. K. Schneeberger, Using next-generation sequencing to isolate mutant genes from forward genetic screens. Nat. Rev. Genet. 15, 662-676 (2014).

27. P. Tornero et al., RAR1 and NDR1 contribute quantitatively to disease resistance in Arabidopsis, and their relative contributions are dependent on the $R$ gene assayed. Plant Cell 14, 1005-1015 (2002).

28. P. Tornero, R. A. Chao, W. N. Luthin, S. A. Goff, J. L. Dangl, Large-scale structure-function analysis of the Arabidopsis RPM1 disease resistance protein. Plant Cell 14, 435-450 (2002).

29. M. J. Axtell, T. W. McNellis, M. B. Mudgett, C. S. Hsu, B. J. Staskawicz, Mutational analysis of the Arabidopsis RPS2 disease resistance gene and the corresponding Pseudomonas syringae avrRpt2 avirulence gene. Mol. Plant-Microbe Interact. 14, 181-188 (2001).

30. J. Zuo, N. H. Chua, Chemical-inducible systems for regulated expression of plant genes. Curr Opin Biotechnol 11, 146-151 (2000).

31. K. Schneeberger et al., Simultaneous alignment of short reads against multiple genomes. Genome Biol. 10, R89 (2009).

32. H. Q. Sun, K. Schneeberger, SHOREmap v3.0: fast and accurate identification of causal mutations from forward genetic screens. Plant Functional Genomics: Methods and Protocols, 2nd Edition 1284, 381-395 (2015). 
Figure 1 made available under aCC-BY-NC-ND 4.0 International license.

A

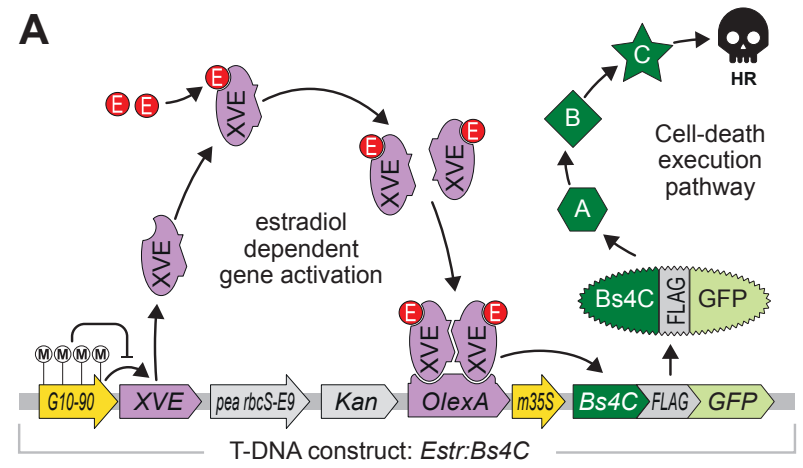

\section{B}

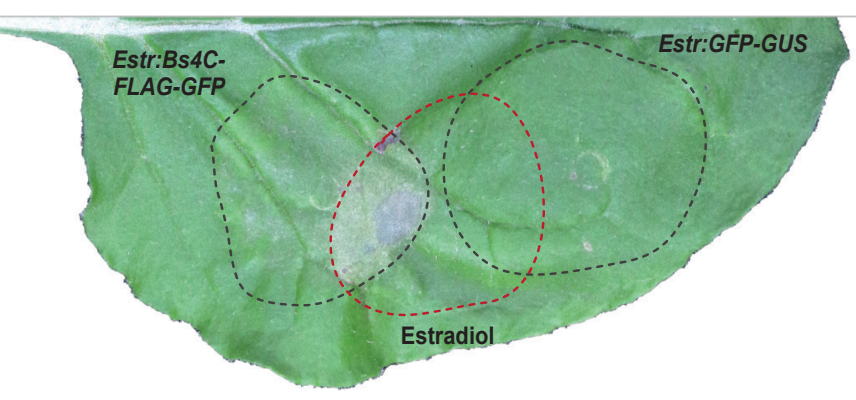

C
Estradiol

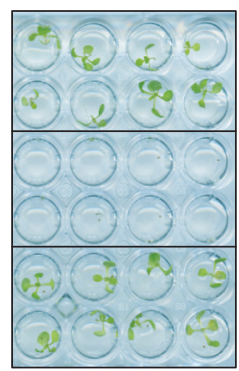

Mock

Estr:GFP-GUS

Estr:Bs4C-

FLAG-GFP

Col-0

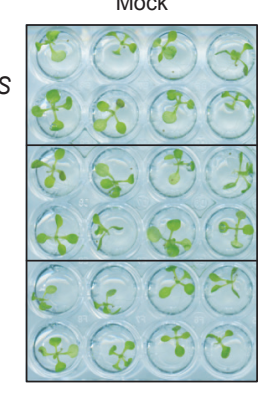

D
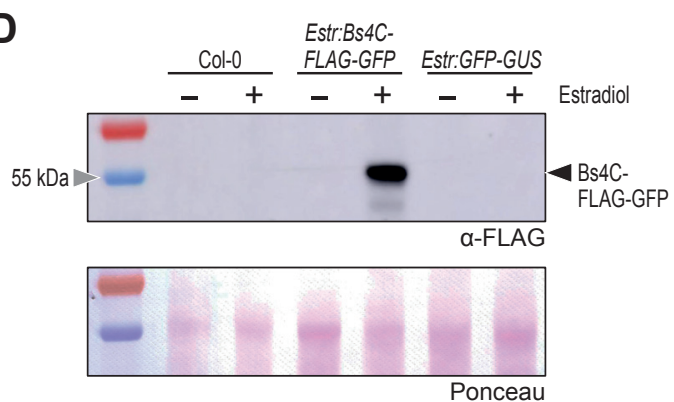

Figure 1. Bs4C induces growth arrest in Arabidopsis.

A | A T-DNA construct for estradiol-inducible expression of the pepper executor protein Bs4C. Driven by the constitutive G10-90 promoter, the XVE gene translates into a chimeric transcriptional activator that contains an estrogen receptor domain. When estrogen $(E)$ is present (here in the form of $\beta$ estradiol), it binds to the XVE protein, mediates XVE homodimerization and enables XVE to bind to the LexA operator (OlexA). This induces transcription of the downstream gene encoding a Bs4C-FLAGGFP protein. The Bs4C fusion protein requires the putative signaling elements $A, B, C$ to trigger plant cell death. Methylation of the G10-90 promoter (M) can cause transcriptional silencing of the G10-90 promoter and results in a non-inducible promoter.

B | A Bs4C transgene triggers estradiol-dependent cell death in Nicotiana benthamiana leaves. The depicted T-DNA constructs were delivered into $N$. benthamiana leaves via Agrobacterium mediated transient transformation. Leaf areas into which the inducer estradiol was infiltrated are highlighted with a red line.

C | An inducible Bs $4 C$ transgene triggers systemic cell death in Arabidopsis. Four day old seedlings of indicated genotypes were placed in liquid media either containing estradiol or a lacking estradiol (Mock). Ten days later, the seedlings show cell death in presence of estradiol and the $B s 4 C$ transgene.

D | Immunoblot analysis using anti-FLAG antibody of tissue from two week old Arabidopsis seedlings of depicted genotypes (Col-0, Estr:Bs4C-FLAG-GFP, Estr:GFP-GUS). Plants were incubated for 24 hours in liquid media either containing estradiol or lacking estradiol (mock). Ponceau stained membrane serves as a loading control. 
bioRxiv preprint doi: https://doi.org/10.1101/2020.06.29.177808; this version posted June 29, 2020. The copyright holder for this preprint (which was not certified by peer review) is the author/funder, who has granted bioRxiv a license to display the preprint in perpetuity. It is

\section{Figure 2} made available under aCC-BY-NC-ND 4.0 International license.

A

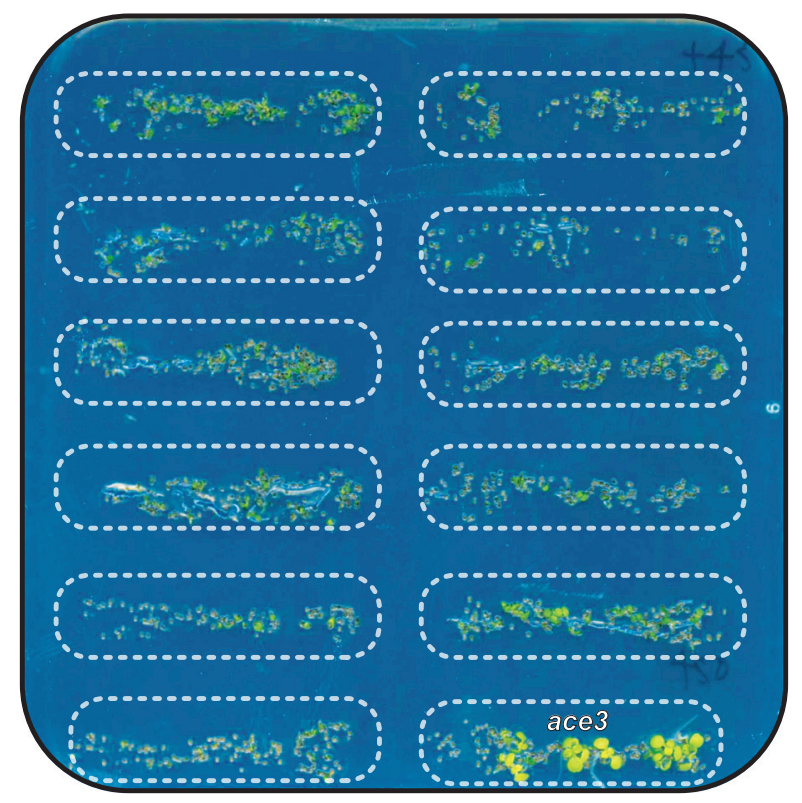

B

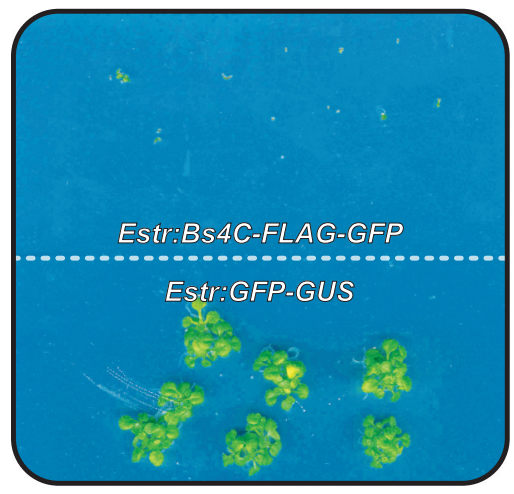

C

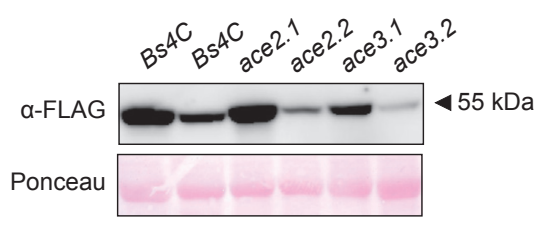

Figure 2. ace screen identifies suppressors of Bs4C-dependent cell death in Arabidopsis.

A I Identification of the ace3 M2 family. Seeds of twelve distinct M2 families are placed in rows on estradiol-containing agar. Boxes framed by dashed lines indicate the region that is covered by seeds of one M2 family. One M2 family (ace3; bottom right) contains individual M2 plants that grow despite the presence of the inducer chemical.

B | Estradiol triggers a Bs4C-dependent cell death reaction. Seeds containing either an estradiolinducible Bs4C (Estr:Bs4C-FLAG-GFP) or a GFP-GUS reporter gene (Estr:GFP-GUS) were placed on an estradiol-containing agar plate.

C | Bs4C protein is expressed in different ace mutants. Immunoblot analysis of five week old Arabidopsis leaves treated with estradiol for 24 hours. Bs4C was detected using an anti-FLAG antibody. Ponceau stain provides an info on total protein content in the samples. 


\section{Figure 3} made available under aCC-BY-NC-ND 4.0 International license.

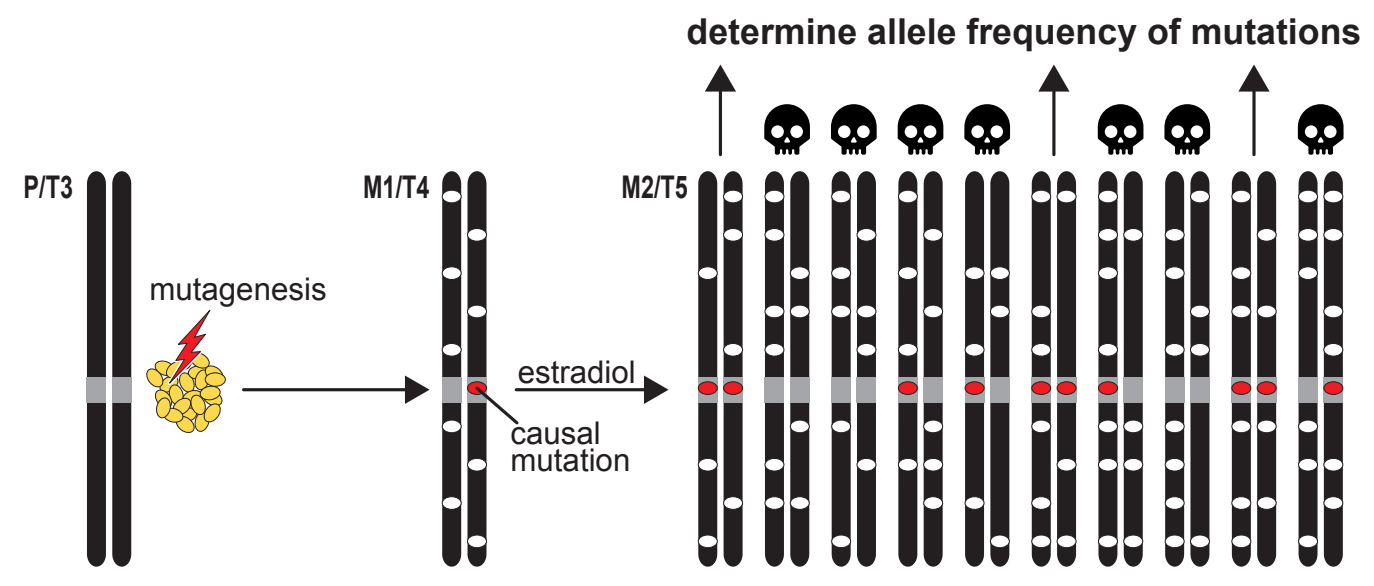

Figure 3. MAD-mapping excludes crosses to expedite isolation of causative mutation.

MAD-mapping identifies causal mutations in the M2 generation. The parental transgenic line (P/T3) contains an inducible transgene (not indicated) that triggers systemic cell death (black skull) upon application of estradiol. Seeds of the parental line were mutagenized by EMS treatment (red arrow) producing M1/T4 plants with EMS-induced mutations (ovals). The causal mutation (red oval), that inhibits activity of the inducible transgene is heterozygous in the M1. EMS mutations of a given M1 segregate in M2/T5 descendants. M2 plants that are homozygous for the causal mutation will survive in presence of the inducer chemical. Survivors of a given M2 family are used to generate DNA pools in which the frequency of EMS-induced mutations is determined by next generation sequencing (NGS). The causal mutation will be homozygous in all survivors and thus will be present at a frequency of 1 $(100 \%)$ in the pool DNA. 
bioRxiv preprint doi: https://doi.org/10.1101/2020.06.29.177808; this version posted June 29, 2020. The copyright holder for this preprint (which was not certified by peer review) is the author/funder, who has granted bioRxiv a license to display the preprint in perpetuity. It is

Figure 4

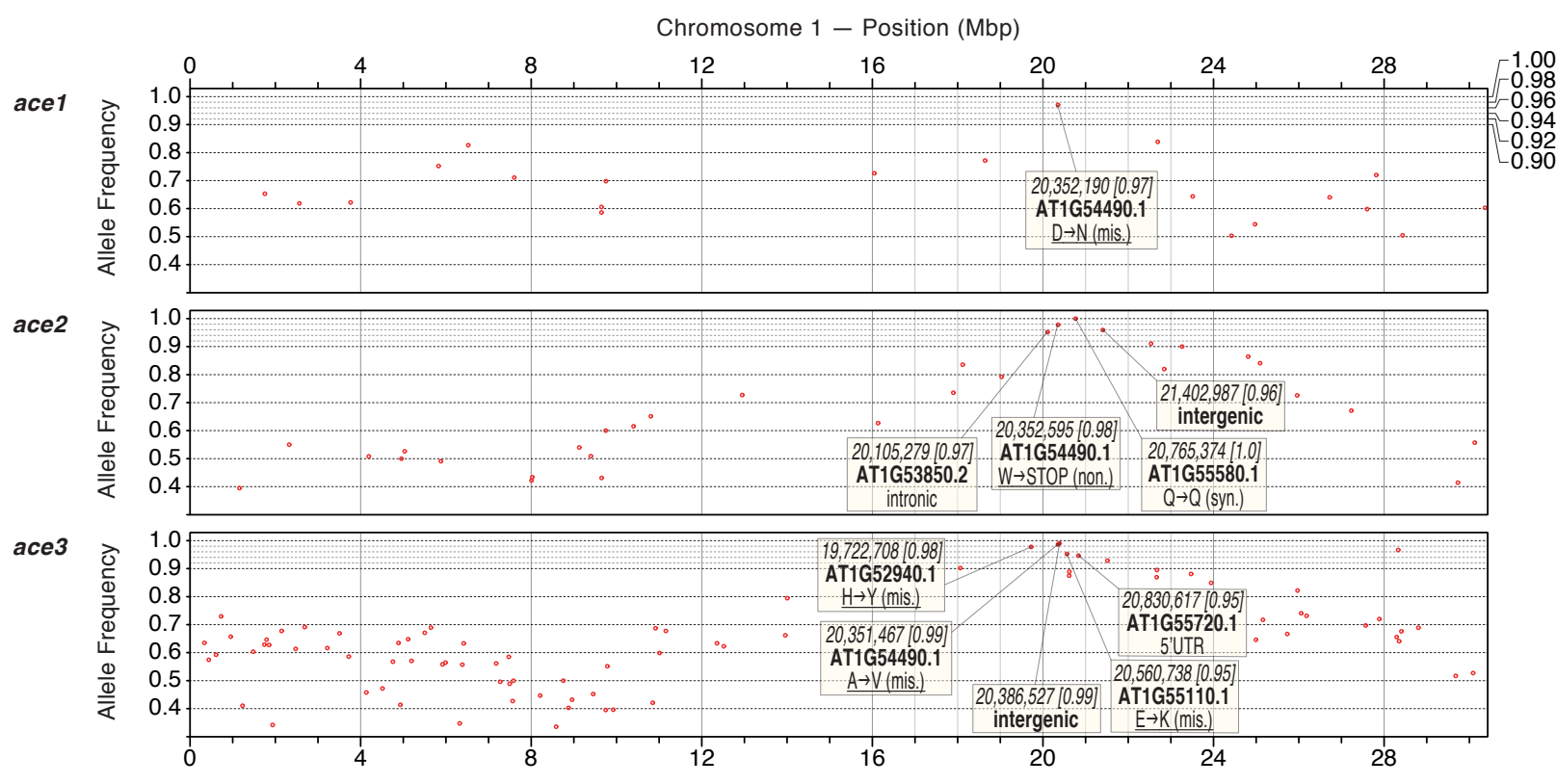

Figure 4. M2 allele frequency-distribution (MAD) mapping identifies mutations in AT1G54490.1 that suppress Bs4C-dependent cell death.

The frequency of EMS-induced mutations (red dots) on chromosome 1 is displayed for ace1, ace 2 and ace3 DNA pools. Boxes provide information on mutations that occur at frequencies of 0.95 or higher. Italic font indicates the chromosomal location of the mutation with the frequency provided in square brackets. Boldface font provides the gene designation. If the mutation is within a gene, the third row reveals the consequences of this mutation. Underlining indicates that the given mutation has likely functional consequences. 
bioRxiv preprint doi: https://doi.org/10.1101/2020.06.29.177808; this version posted June 29, 2020. The copyright holder for this preprint (which was not certified by peer review) is the author/funder, who has granted bioRxiv a license to display the preprint in perpetuity. It is

Figure 5

A

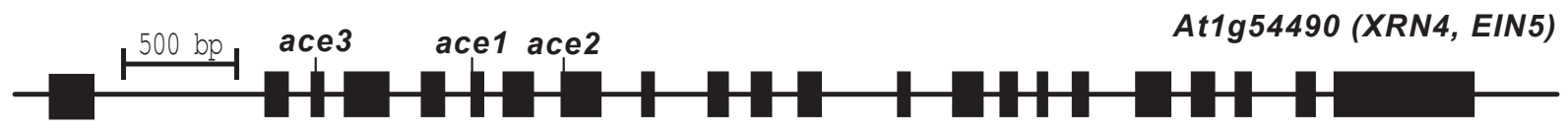

B

$$
\begin{aligned}
& \text { wildtype }\left[\begin{array}{c}
\text { GCCGAGAGCAAAGAT } \\
\mathrm{P}
\end{array}\right. \\
& 1359 \\
& \operatorname{mutant} \underset{\mathrm{P}}{\mathrm{R}} \underset{\mathrm{V}}{\mathrm{G} C \mathrm{GAG}} \frac{\mathrm{A} A \mathrm{~A} A \mathrm{~T}}{\mathrm{M}}
\end{aligned}
$$
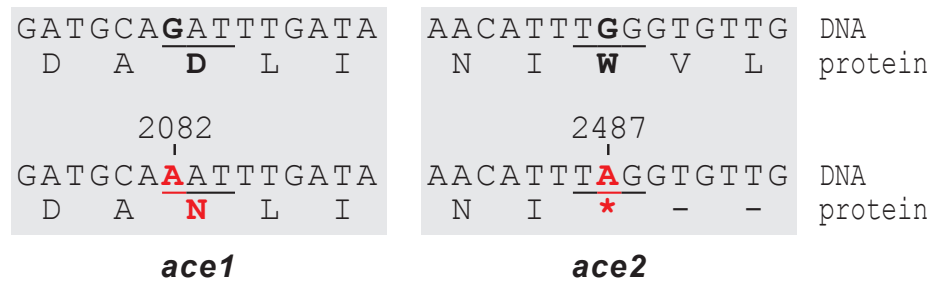

Figure 5. ace families harbor distinct mutations in AT1G54490.1.

A | Location of mutations in ace1, ace2, and ace 3 mutants. Black boxes represent AT1G54490.1 exons. The location of each causal mutations in ace3, ace1, and ace2, is indicated. Black bar indicates length of $500 \mathrm{bp}$.

B | Mutations in ace mutants and its consequences at the protein level. Underlined letters indicate the affected codons with the encoded amino acid shown below. Letters in black bold display the base pair or amino acid found in the parental line. Red bold font indicates EMS-induced mutations with the encoded amino indicated below. Numbers above mutated base pairs indicate positions of the mutations within the transcript sequence. An asterisk $\left(^{*}\right)$ indicates a translational stop codon. 
bioRxiv preprint doi: https://doi.org/10.1101/2020.06.29.177808; this version posted June 29, 2020. The copyright holder for this preprint (which was not certified by peer review) is the author/funder, who has granted bioRxiv a license to display the preprint in perpetuity. It is

\section{Figure S1}
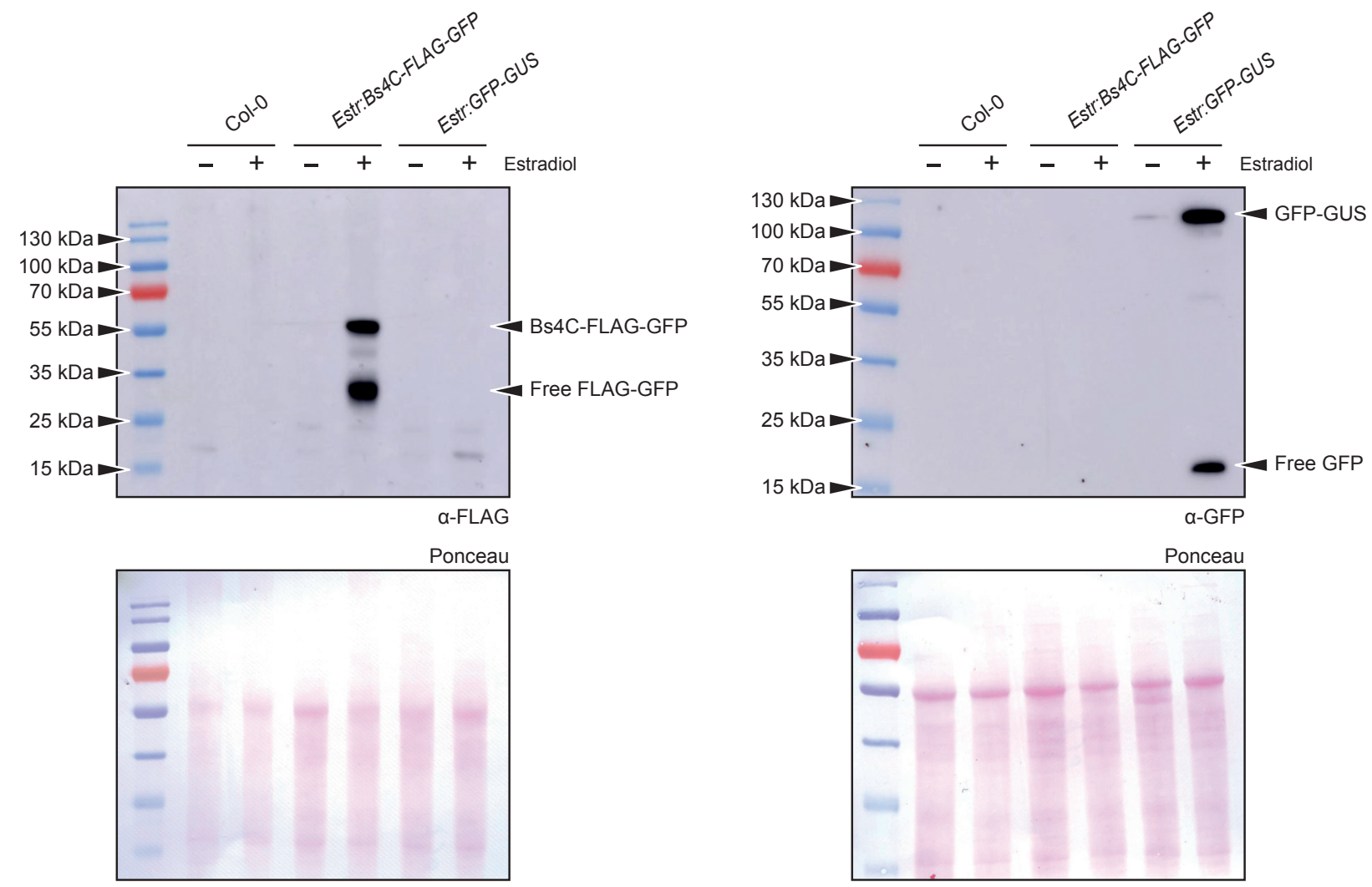

Figure S1. | Transgenic lines containing inducible transgenes express transgene-encoded proteins in an estradiol-dependent fashion. Immunoblot analysis using anti-FLAG and anti-GFP antibody of tissue from two week old Arabidopsis seedlings of depicted genotypes (Col-0, Estr:Bs4CFLAG-GFP, Estr:GFP-GUS). Plants were incubated for 24 hours in liquid media either containing estradiol or lacking estradiol (mock). Ponceau stained membrane serves as a loading control. Molecular mass markers are indicated by triangles. 
bioRxiv preprint doi: https://doi.org/10.1101/2020.06.29.177808; this version posted June 29,2020 . The copyright holder for this preprint (which was not certified by peer review) is the author/funder, who has granted bioRxiv a license to display the preprint in perpetuity. It is Figure $\mathbf{S 2}$

ace1
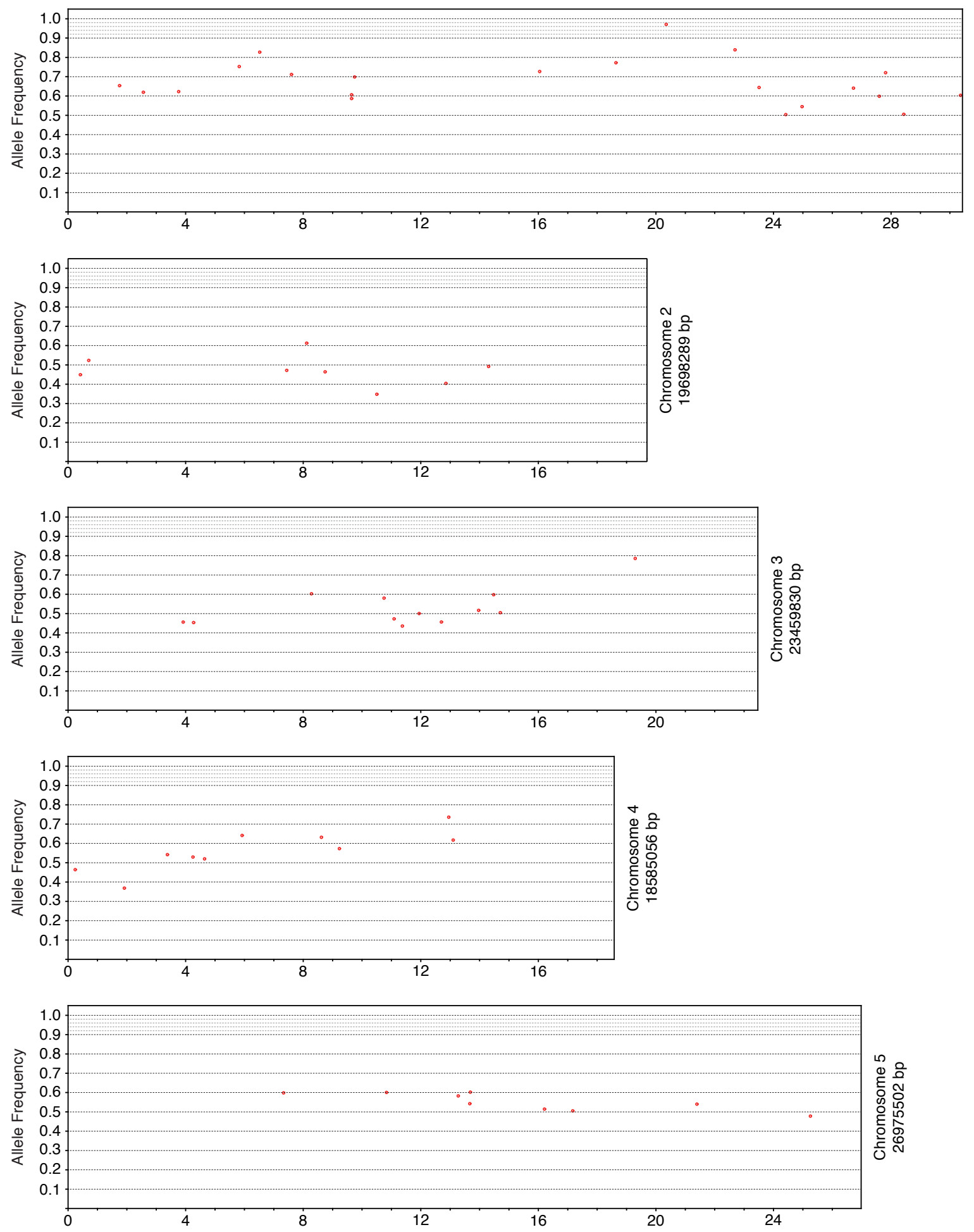

Figure S2. | M2 allele frequency-distribution in the ace1 mutant family. The frequency and position of EMS-induced mutations (red dots) on chromosome 1-5 are displayed. 
bioRxiv preprint doi: https://doi.org/10.1101/2020.06.29.177808; this version posted June 29,2020 . The copyright holder for this preprint (which was not certified by peer review) is the author/funder, who has granted bioRxiv a license to display the preprint in perpetuity. It is Figure S3

ace2
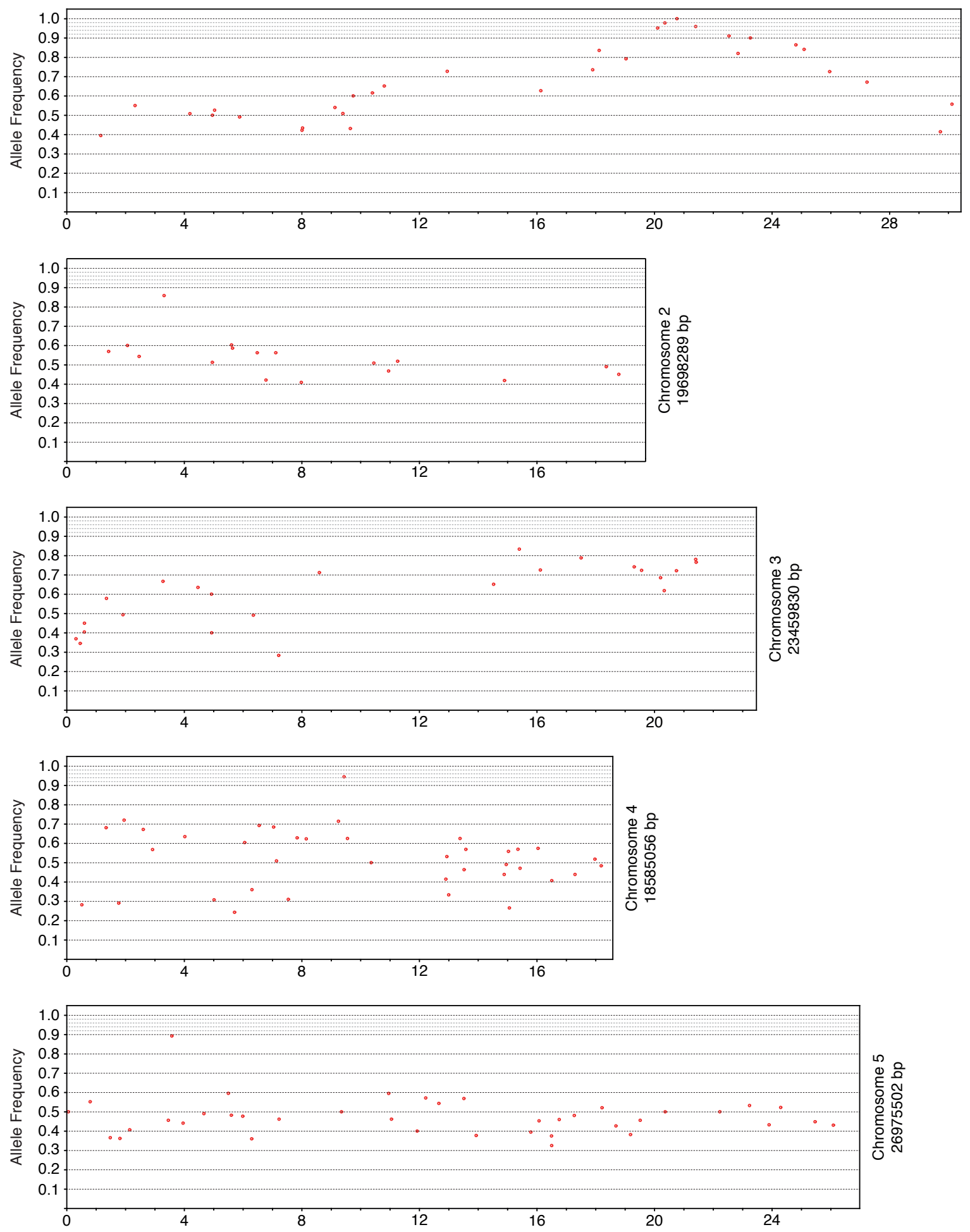

Figure S3. | M2 allele frequency-distribution in the ace2 mutant family. The frequency and position of EMS-induced mutations (red dots) on chromosome 1-5 are displayed. 
bioRxiv preprint doi: https://doi.org/10.1101/2020.06.29.177808; this version posted June 29,2020 . The copyright holder for this preprint (which was not certified by peer review) is the author/funder, who has granted bioRxiv a license to display the preprint in perpetuity. It is

\section{Figure S4} made available under aCC-BY-NC-ND 4.0 International license.

ace3
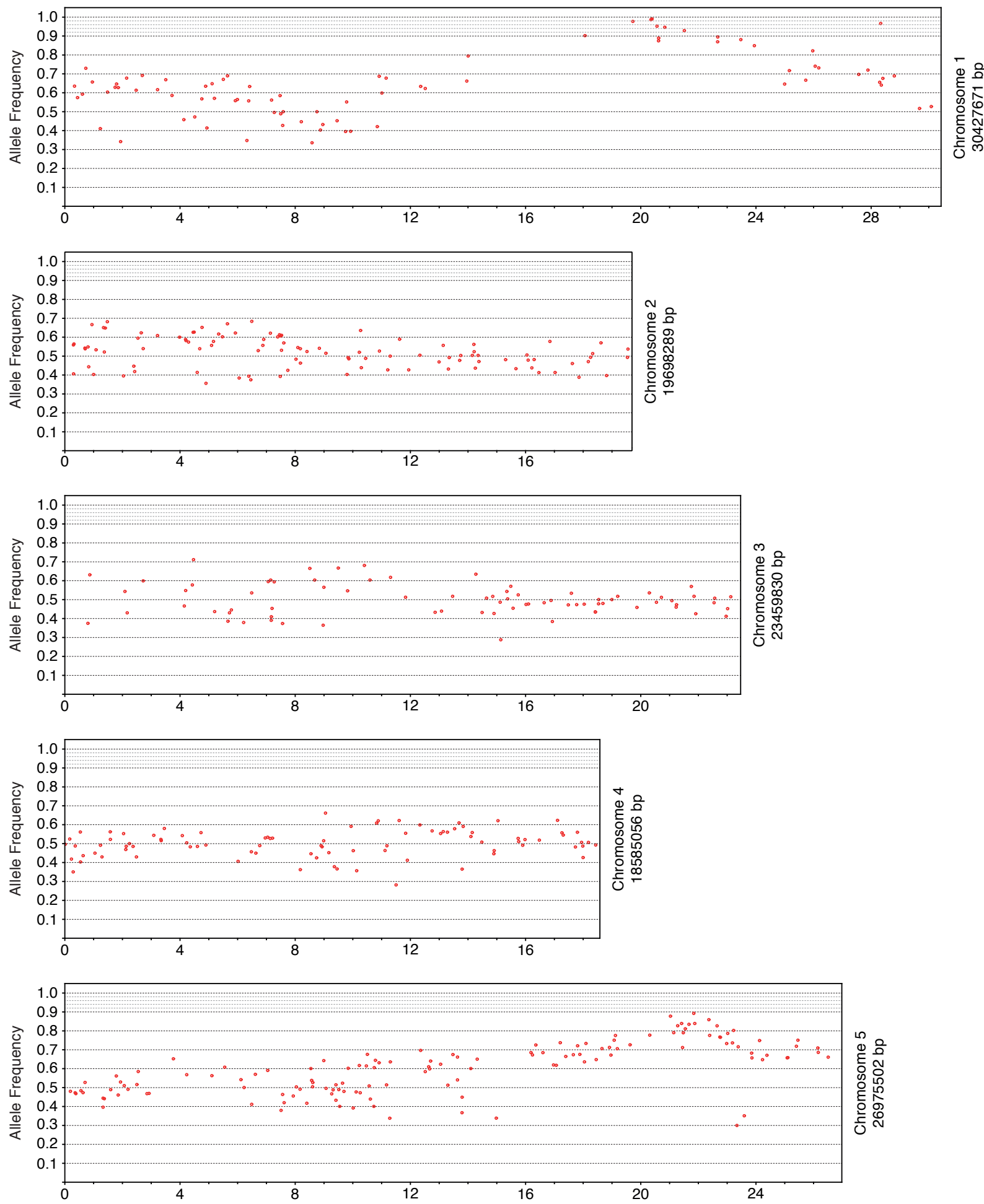

Figure S4. | M2 allele frequency-distribution in the ace 3 mutant family. The frequency and position of EMS-induced mutations (red dots) on chromosome 1-5 are displayed. 
bioRxiv preprint doi: https://doi.org/10.1101/2020.06.29.177808; this version posted June 29, 2020. The copyright holder for this preprint (which was not certified by peer review) is the author/funder, who has granted bioRxiv a license to display the preprint in perpetuity. It is

Figure S5 made available under aCC-BY-NC-ND 4.0 International license.

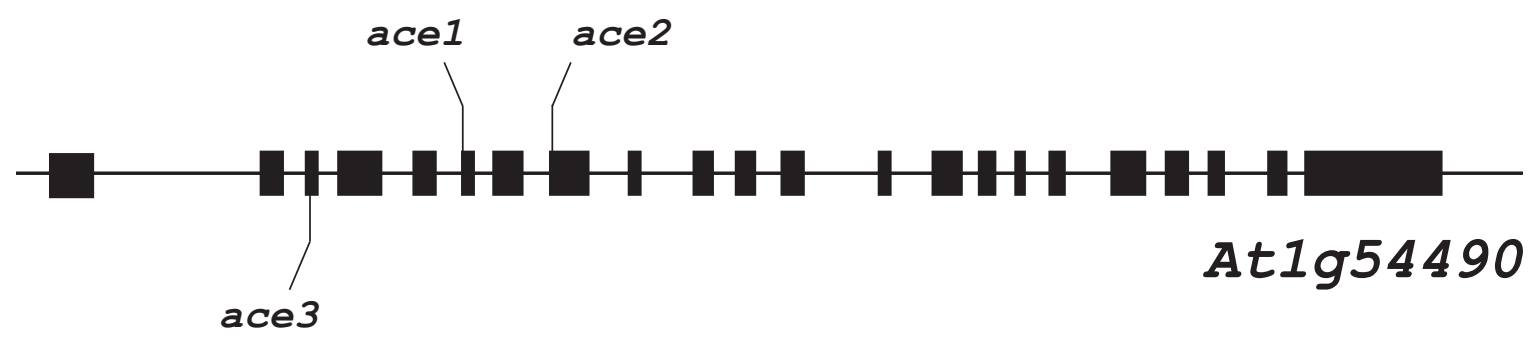

WT

AGATGGAGTTGCGCCGAGAGCAAAGATGAATCAGCAGCGTTCTCGACGTTTC

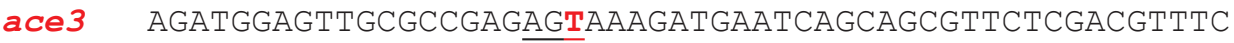

ace2 AGATGGAGTTGCGCCGAGAGCAAAGATGAATCAGCAGCGTTCTCGACGTTTC

$\operatorname{ace} 1$ $\begin{array}{llllllllllllllllllll}D & G & V & A & P & R & \mathbf{A} & K & M & N & Q & Q & R & S & R & R & F\end{array}$

WT atattattatgcagGATGCAGATTTGATAATGCTCTCCTTAGCTACACAT

ace1 atattattatgcagGATGCAAATTTGATAATGCTCTCCTTAGCTACACAT

ace2 atattattatgcagGATGCAGATTTGATAATGCTCTCCTTAGCTACACAT

ace3 atattattatgcagGATGCAGATTTGATAATGCTCTCCTTAGCTACACAT

WT

ace2 AAATATCAGTTCCTGAACATTTAGGTGTTGCGAGAATATCTGCAATATGAA

Figure S5. | Mutations in ace families are independent from one another. Underlined letters indicate the 3 letter codon corresponding to the amino acid directly below. Letters in black bold display reference base pair or amino acid found in the parental line, and letters in red bold designate altered base pair or amino acid found in indicated mutant family. 